\title{
The influence of anti-zona and anti-sperm antibodies on sperm-egg interactions
}

\author{
R. J. Aitken, E. A. Rudak, D. W. Richardson, J. Dor, O. Djahanbahkch \\ and A. A. Templeton
}

M.R.C. Unit of Reproductive Biology, 37 Chalmers Street, Edinburgh EH3 9EW, U.K.

\begin{abstract}
Summary. Anti-zona antibodies are effective inhibitors of fertilization in vitro and, regardless of whether passive or active immunization techniques are used, in vivo. Antibodies raised against unfractionated zona pellucida antigens are chiefly directed against a group of carbohydrate-rich components localized on the outer surface of the zona. The interaction of anti-zona antibodies with these sites induces the formation of a surface precipitate which occludes the sperm binding sites by a process of steric hindrance, and stabilizes the zona structure against digestion by the proteolytic enzymes of the sperm head. Active immunization studies indicate that the long-term induction of infertility without adverse side effects is feasible in both laboratory rodents and primates when the zona pellucida is used as a target.

Anti-sperm antibodies also exhibit a capacity for inhibiting fertilization in vivo and in vitro. To determine the most appropriate detection method to screen patients for anti-sperm antibodies several homologous and heterologous antisera were analysed by 5 different agglutination and immobilization techniques and then compared for their ability to inhibit the fertilizing capacity of human spermatozoa using the zona-free hamster egg penetration test. The results obtained with the Franklin-Dukes tube-slide test exhibited the closest correlation with the anti-fertility activity of a given antiserum; this activity could be amplified by the addition of complement to the medium. It is concluded that antibodies directed against the sperm head are responsible for limiting the fertilizing capacity of human spermatozoa in vitro and that it is these antibodies on which attention should be focused to unravel the role that immunological factors play in the aetiology of infertility in vivo.
\end{abstract}

\section{Introduction}

An assessment of the ability of antibodies to interfere with the union of male and female gametes during fertilization may be of significance in elucidating the role played by immunological factors in the aetiology of infertility and in developing an immunological approach to contraception. It is the purpose of this article to consider these topics and, in particular, to examine the capacity of anti-zona and anti-sperm antibodies to disrupt the sequence of spermegg interactions that constitute the fertilization process.

\section{Anti-zona antibodies}

The zona pellucida is a translucent acellular glycoprotein shell which is deposited around the oocyte during folliculogenesis and serves (a) to bind spermatozoa during the early stages of 
fertilization, (b) to participate in the block to polyspermy in certain species, e.g. the hamster, and (c) to protect and isolate the embryo during the preimplantation stages of development. The idea of using this structure as a target for a contraceptive vaccine first evolved when it was discovered that the exposure of unfertilized hamster eggs to antisera raised against aqueous extracts of homologous ovarian tissue effectively biocked their ability to become fertilized in vitro (Shivers, Dudkiewicz, Franklin \& Fussell, 1972). Subsequently numerous studies of similar design have confirmed the antifertility activity of heteroimmune anti-ovary antisera in rats (Tsunoda \& Chang, 1976a) and mice (Jilek \& Pavlok, 1975; Tsunoda \& Chang, 1977). The inhibitory effects of these antisera can be neutralized by absorption with aqueous ovarian extracts in the hamster (Oikawa \& Yanagimachi, 1975), mouse (Tsunoda \& Chang, 1976b) and rat (Tsunoda \& Chang, 1976a). In contrast, absorption with somatic tissues does not reduce their efficacy in mice (Tsunoda \& Chang, 1977) and hamsters (Oikawa \& Yanagimachi, 1975 ), indicating that, in these species at least, specific ovarian antigens are involved in eliciting the formation of those antibodies responsible for the induction of infertility.

The probable nature of these ovarian antigens was revealed when it was observed that the most antigenic component of the ovary is the zona pellucida in the rabbit (Sacco \& Shivers, 1973), hamster (Oikawa \& Yanagimachi, 1975), guinea-pig (Porter, Highfill \& Winovich, 1970), mouse (Glass \& Hanson, 1974), rat (Tsunoda \& Chang, 1976a), cow (Shivers, 1974), pig (Sacco, 1977) and man (Sacco, 1977). Subsequent to these observations more specific antisera have been prepared against cumulus-free mouse ova (Tsunoda, 1977), mechanically isolated mouse zonae pellucidae (Tsunoda \& Chang, 1978) and heat-solubilized hamster zonae (Gwatkin, Williams \& Carlo, 1977) and shown to be potent inhibitors of fertilization in vitro.

Table 1. Correlation between the ability of anti-zona antisera (raised against cumulus-free mouse ova) to inhibit sperm binding with their ability to induce a precipitate on the outer zona surface

\begin{tabular}{lcccc}
\hline Intensity of precipitate & $0^{*}$ & + & ++ & +++ \\
$\%$ inhibition of sperm binding (mean \pm s.e.m.) & $11 \cdot 1 \pm 2 \cdot 8$ & $47 \cdot 2 \pm 5 \cdot 2$ & $66 \cdot 1 \pm 6 \cdot 3$ & $77 \cdot 4 \pm 4 \cdot 4$ \\
No. of observations & 21 & 13 & 12 & 20 \\
\hline
\end{tabular}

* Anti-zona antibodies detected in these antisera by immunofluorescence but failing to produce zona precipitate.

Such antisera appear to achieve their inhibitory effects in vitro by preventing both the binding of spermatozoa to specific receptor sites on the zona pellucida and the subsequent penetration of spermatozoa through to the perivitelline space (Aitken \& Richardson, 1981). The inhibition of sperm binding appears, in turn, to be due to the ability of anti-zona antibodies to induce the formation of a precipitate on the outer surface of the zona pellucida (Table 1, Pl. 1, Fig. 1) (Shivers et al., 1972; Jilek \& Pavlok, 1975; Aitken \& Richardson, 1981). The surface localization of this precipitate is not simply a question of limited antibody access to the deeper regions of the zona since a precipitate is only formed on the outer surface of isolated zona fragments (R. J. Aiken \& D. W. Richardson, unpublished observations). In the rat, mouse and hamster the outer zona surface is characterized by a high concentration of terminal saccharide groups which, in view of their affinity for Ricinus communis and wheat germ agglutinins, contain a high concentration of D-galactose and $\mathrm{N}$-acetyl-D-glucosamine (or $\mathrm{N}$ acetylneuraminic acid) residues (Nicolson, Yanagimachi \& Yanagimachi, 1975). The presence of these carbohydrate groups at the zona surface presumably enhances the immunogenicity of this region so that when antisera are raised against intact zonae pellucidae a majority of the antibodies are directed against these surface components. The terminal saccharide groups presumably play no part in the sperm binding capacity of the zona since spermatozoa will bind avidly to both the inner and outer surfaces of isolated zona fragments (Gwatkin \& Williams, 1977; R. J. Aitken \& D. W. Richardson, unpublished observations). Consequently, the precipitate which is induced at the zona surface by anti-zona antibodies must block the ability of spermatozoa to associate with their binding sites by a process of steric hindrance 
PLATE i
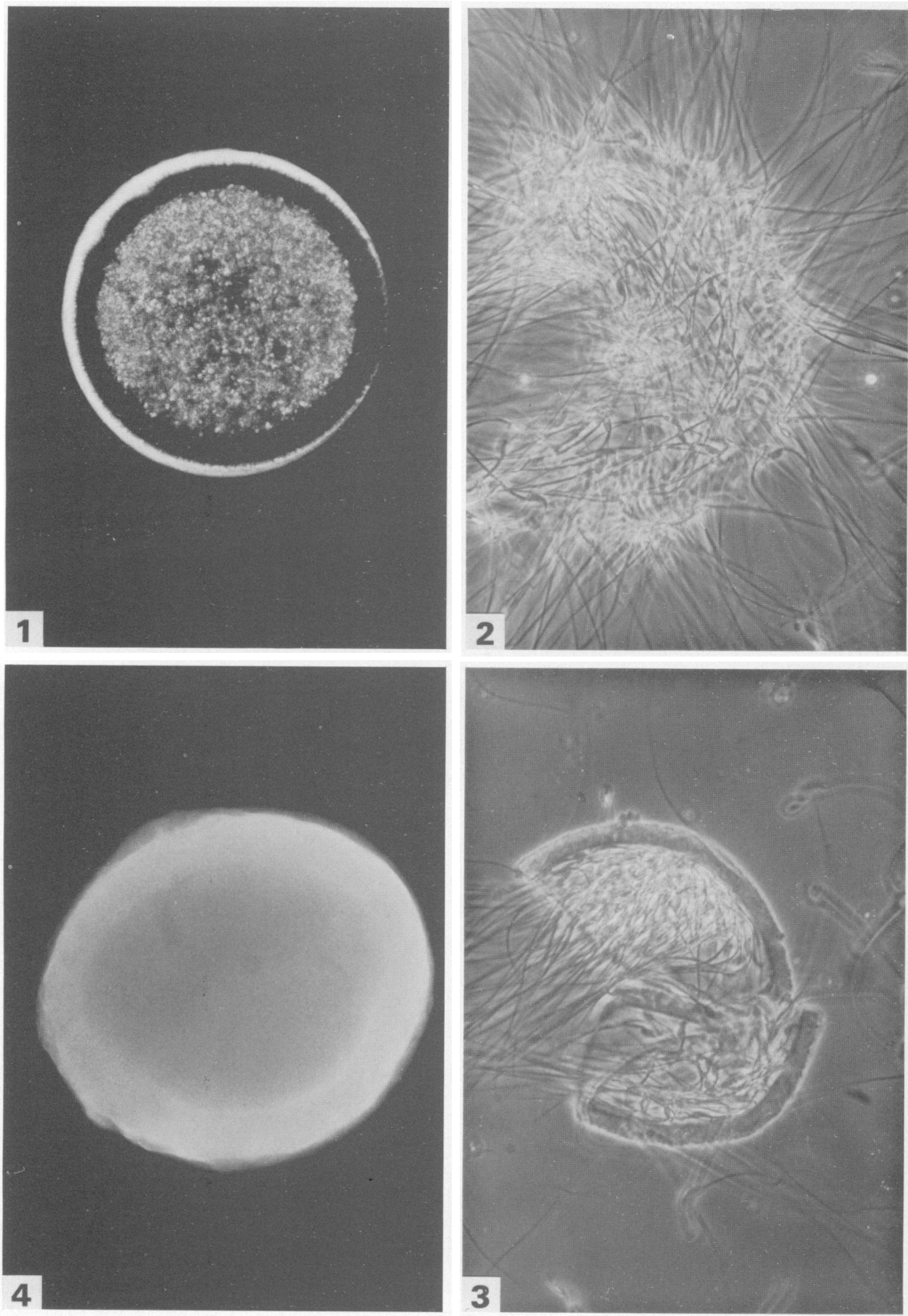

(Facing p. 598) 
rather than by direct interaction with the receptors. This conclusion is supported by the fact that treatment of mouse zona fragments with antibodies raised against mechanically isolated zonae blocks sperm binding to the outer zona surface, in association with the formation of a precipitate in this area, but not to the inner surface, where the receptors remain unimpeded (Pl. 1, Figs 2 and 3). The possibility that an inefficient process such as steric hindrance is responsible for mediating the effects of anti-zona antibodies on sperm binding is also suggested by the finding that serial dilutions of such antisera results in a precipitous loss of inhibitory activity within 20-30 dilution steps (Text-fig. 1).

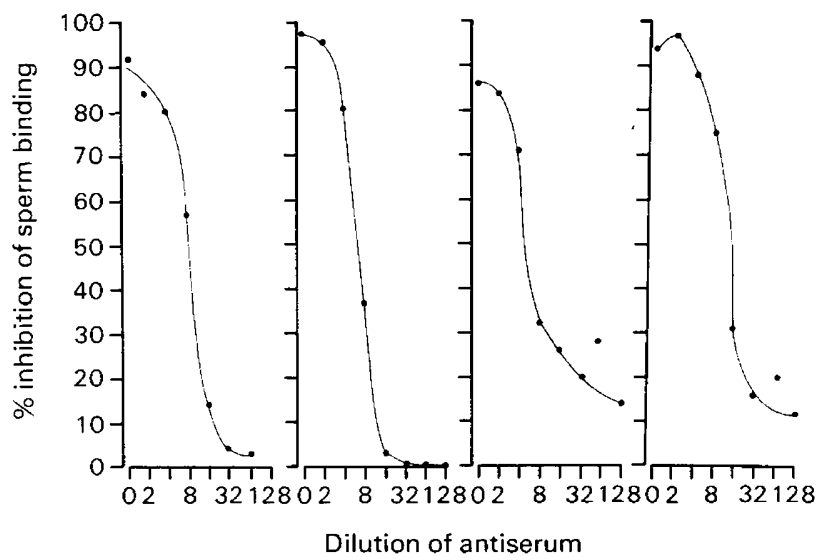

Text-fig. 1. Antibody dilution curves for 4 antisera raised against cumulus-free ova. In each case there is a precipitous loss of the ability to inhibit sperm binding within 20-30 dilution steps.

These findings have important implications with respect to the strategy we employ to develop an anti-zona vaccine for fertility regulation. The anti-fertility activity of most, if not all, the anti-zona antisera tested to date (Aitken \& Richardson, 1981) is due to antibodies raised against highly antigenic surface components which are adjacent to, but not equivalent to, the receptors for spermatozoa. Since the sperm receptor present in hamster zonae pellucidae is sensitive to trypsin treatment (Gwatkin, 1977) and yet stable when heated to $100^{\circ} \mathrm{C}$ (Gwatkin \& Williams, 1977), it is possible that these structures are small molecular weight proteins or peptides which consequently exhibit little antigenicity. However, it is the predicted small size of these receptors and, in particular, their critical biological activity that makes them such ideal targets for contraceptive purposes. The isolation of these components and the production of specific antisera directed against them are therefore important tasks for the future.

Despite their inefficient mechanism of action antisera raised against intact zona pellucida antigens are, nevertheless, potent inhibitors of fertility in vivo as well as in vitro. Hence passive immunization of hamsters (Oikawa \& Yanagimachi, 1975; Tsunoda \& Chang, 1976a), mice (Jilek \& Pavlok, 1975) and rats (Tsunoda \& Chang, 1976a) with either whole antisera, or crude $\gamma$-globulin preparations, raised against aqueous ovarian extracts, has been found to be extremely effective in blocking fertility. In addition, intraperitoneal injections of $\gamma$-globulin preparations directed against cumulus-free mouse eggs or mechanically isolated zonae pellucidae are equally effective at inhibiting fertilization in vivo (Tsunoda \& Chang, 1978; Sacco, 1979). One remarkable feature of such passive immunization procedures is the prolonged suppression of fertility observed after the administration of a single injection of antiserum. Oikawa \& Yanagimachi (1975) observed that the fertilization of hamster oocytes was completely blocked for 12 days after the passive administration of an anti-ovary $\gamma$-globulin preparation and that fertility was partly suppressed for a further 16 days. Single administrations of specific antisera 
produced against mechanically isolated mouse zonae pellucidae have also been shown to block fertilization for 24-30 days (Tsunoda \& Sugie, 1977; Sacco, 1979). The prolonged activity of anti-zona antibodies in vivo appears to be due to their ability to bind to the zonae surrounding follicular as well as ovulated oocytes (Oikawa \& Yanagimachi, 1975). The effectiveness of these antisera in vivo, as in vitro, appears to be related to their ability to induce the formation of a precipitate at the zona surface, thereby occluding the sperm binding sites and rendering the zona resistant to solubilization by the proteolytic enzymes contained within the sperm head (Aitken \& Richardson, 1981). Hence, the zonae pellucidae encapsulating oocytes recovered from passively immunized animals invariably exhibit both the presence of a surface precipitate and an increased resistance to digestion by lytic agents (Oikawa \& Yanagimachi, 1975; Tsunoda \& Chang, 1976a, b, 1978).

Active immunization procedures are also effective at inducing a state of infertility in association with high anti-zona antibody titres. The development of such active immunization models has been facilitated by the existence of a considerable degree of cross-reactivity between the zona antigens of different mammalian species. As an example, cross-reactivity has been demonstrated between rat and mouse zonae pellucidae by indirect immunofluorescence, complement fixation and immunoprecipitation techniques (Aitken \& Richardson, 1981). In addition, similarities appear to exist in the conformation of the sperm binding sites between these species since mouse spermatozoa will bind avidly to rat zonae and vice versa (Table 2). Active immunization of rats with aqueous extracts of mouse ovarian tissue or cumulus-free ova has been shown to result in the production of high anti-zona antibody titres and associated infertility (Aitken \& Richardson, 1981). In contrast, control animals immunized against mouse serum proteins exhibited neither detectable antibody titres nor any curtailment of their fertility (Table $3)$. In the zona-immunized animals a fall in antibody titre within 20 weeks of completing the immunization schedule invariably resulted in conception. Such post-immunity conceptions appeared to result in normal pregnancies and the eventual birth of normal healthy young which were subsequently shown to be fertile (Text-fig. 2b). If antibody titres remained high for more than 5 months the immunized animals never conceived despite repeated matings (Text-fig. 2a).

Table 2. The binding affinity of mouse and rat spermatozoa for receptor sites on rat and mouse zonae pellucidae

\begin{tabular}{|c|c|c|c|}
\hline \multirow[b]{2}{*}{ Exp. } & \multicolumn{2}{|c|}{ Species of: } & \multirow{2}{*}{$\begin{array}{l}\text { Conc. of } \\
\text { spermatozoa bound } / \mathrm{mm}^{2} \\
\text { zona surface }\end{array}$} \\
\hline & Zona pellucida & Spermatozoa & \\
\hline \multirow[t]{2}{*}{1} & Mouse & Mouse & $5045 \pm 191$ \\
\hline & Rat & Mouse & $4172 \pm 152$ \\
\hline \multirow[t]{2}{*}{2} & Mouse & Mouse & $5165 \pm 147$ \\
\hline & Rat & Mouse & $4675 \pm 652$ \\
\hline \multirow[t]{2}{*}{3} & Mouse & Mouse & $2954 \pm 173$ \\
\hline & Rat & Mouse & $2947 \pm 151$ \\
\hline \multirow[t]{2}{*}{4} & Mouse & Mouse & $5165 \pm 147$ \\
\hline & Mouse & Rat & $3266 \pm 254$ \\
\hline
\end{tabular}

Values are mean \pm s.e.m. for $8-10$ observations.

Table 3. Fertility of rats actively immunized against mouse serum proteins or cumulus-free ova

\begin{tabular}{lcccc}
\hline \multicolumn{1}{c}{ Immunogen } & $\begin{array}{c}\text { No. of } \\
\text { animals }\end{array}$ & $\begin{array}{c}\text { No. of } \\
\text { matings }\end{array}$ & $\begin{array}{c}\text { No. of } \\
\text { animals pregnant }\end{array}$ & $\begin{array}{c}\text { \% animals } \\
\text { exhibiting infertility }\end{array}$ \\
\hline Serum & 7 & 8 & 7 & 0 \\
Cumulus-free ova & 14 & 80 & 10 & 100 \\
\hline
\end{tabular}



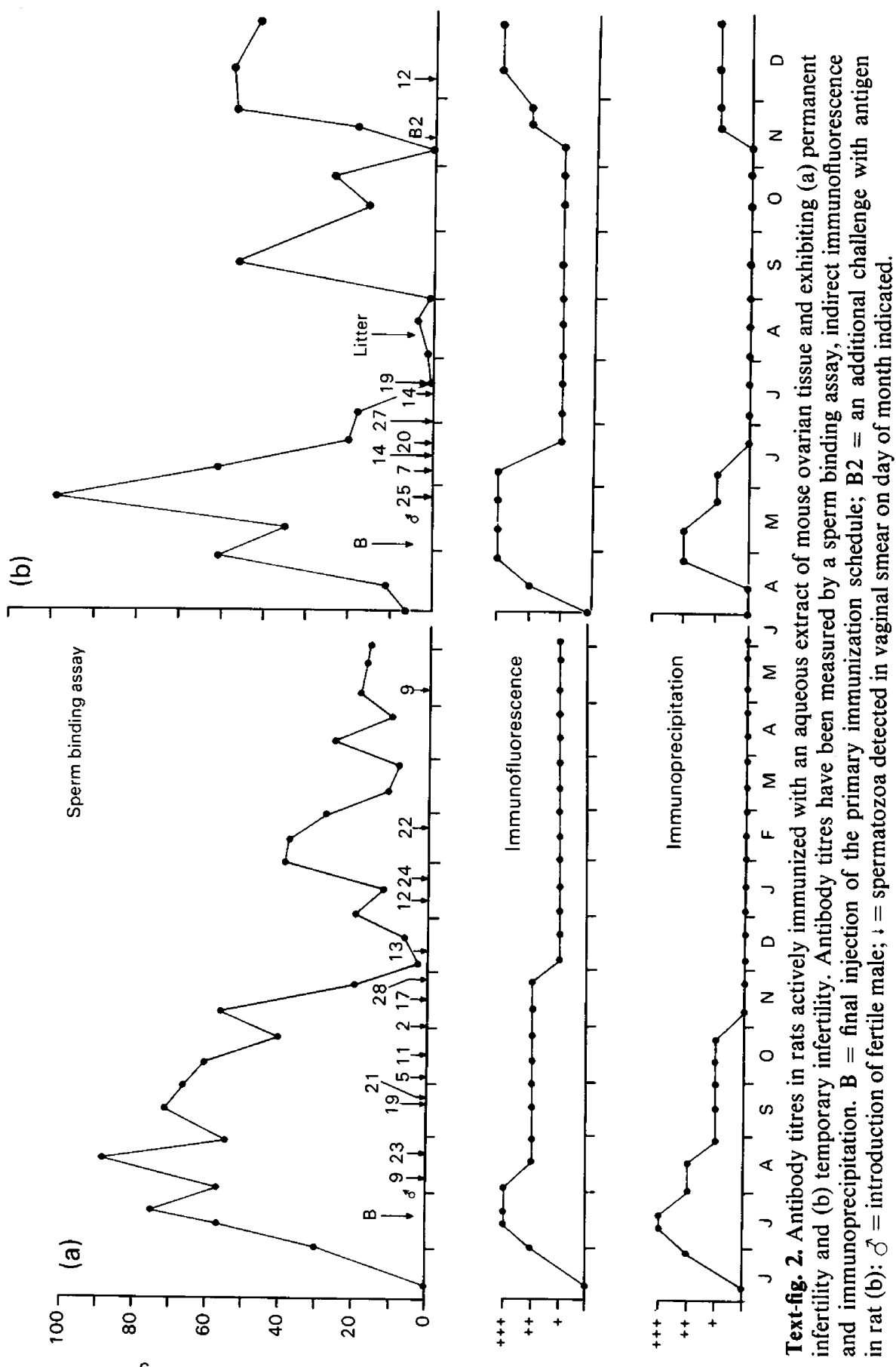

bu!pu!q to uo!!!q!4u! \% 
Overt adverse side-effects have not been observed in any of the 25 animals immunized to date with the single exception of a uterine haematoma observed in an ageing female autopsied when antibody titres had declined to $30 \%$ sperm binding inhibition. This lesion probably represents the location of a resorbing conceptus since histological examination of the site revealed the presence of polyploid trophoblast-like cells. Whether the presence of anti-zona antibodies played any aetiological role in the abortion of this embryo cannot easily be ascertained. The possibility that there are antigens on the surface of the conceptus which cross-react with the zona pellucida is currently being investigated. In general, however, these active immunization studies have yielded encouraging results to indicate that the long-term induction of infertility without adverse side effects is achievable through the induction of immunity against the zona pellucida. Similar results have been obtained in active immunization experiments in which mice were immunized with heat-solubilized hamster zonae and found to exhibit infertility in association with high antibody titres (Gwatkin et al., 1977).

These active immunization experiments are currently being extended to include primates. A number of opportunities for constructing such a model exist since there is extensive crossreactivity between the zona antigens of primates and species suitable for large scale extraction of zona material, particularly ungulates and rodents. Antisera raised against heat-solubilized hamster zonae will, for example, bind to rhesus and squirrel monkey eggs (Gwatkin et al., 1977), while antisera raised against mechanically isolated bovine or murine zonae pellucidae will bind avidly to marmoset zonae (R. J. Aitken \& M. Hulme, unpublished observations; Pl. 1, Fig. 4). The completion of such studies will provide valuable information on the correlation between infertility and anti-zona antibody titres, the duration and reversibility of the infertility induced and the presence or absence of harmful side effects. Such primate studies will also, of course, bring us one step closer to such procedures for man. The ultimate demonstration of the feasibility of this approach to contraception in our own species, however, would be to identify cases of infertility in which the cause could be related to the presence of circulating anti-zona antibodies. One such study (Mori et al., 1979), employing the ability of human immunoglobulins to bind to porcine zonae as the method of assessment, has claimed that about $15 \%$ of the infertile women investigated possessed such antibodies. This report will have to be confirmed using more precise detection methods but as it stands this result is extremely encouraging.

The possibility of developing an anti-zona vaccine will also depend, to a large extent, on the nature of the antigens responsible for the induction of infertility. The large-scale administration of heterologous antigens for contraceptive purposes would seem impractical and hence the only alternative will be to synthesize artificial analogues of the critical zona components. The carbohydrate-rich surface antigens responsible for the induction of infertility when intact zonae are used as the immunogen are rich in D-galactose and $N$-acetyl-D-glucosamine residues. A detailed study of the biochemical composition of porcine zonae pellucidae has revealed that 2 of these surface antigens have sub-unit molecular weights of between 50000 and 70000 (Dunbar \& Raynor, 1980). Further characterization of these constituents is in progress and valuable information on their molecular configurations should become available. We can

\section{PLATE 1}

Fig. 1. Induction of a precipitate on the outer surface of a cow zona pellucida by an antiserum raised against isolated cow zonae pellucidae.

Fig. 2. Binding of mouse spermatozoa to both sides of isolated mouse zona fragments.

Fig. 3. Inhibition of sperm binding to the outer but not the inner surface of mouse zona fragments in the presence of antibodies raised against isolated mouse zonae pellucidae.

Fig. 4. Indirect immunofluorescence of a marmoset zona pellucida treated with an antiserum raised against isolated cow zonae pellucidae. 
anticipate, however, that the difficulties encountered in producing synthetic analogues of such large molecules, the immunological uniqueness of which depends upon a 3-dimensional conformation (Dunbar \& Raynor, 1980), are likely to prove insurmountable. A possible solution to this problem might be to focus on the components of the zona responsible for its sperm binding capacity which, for reasons given earlier, are likely to be much smaller molecules than the surface glycoproteins.

\section{Anti-sperm antibodies}

Since the original discovery of autoantibodies directed against sperm antigens in infertile men by Wilson (1954) and Rumke (1954) controversy has raged not as to the existence of such antibodies but rather their role in the aetiology of infertility. The extreme expression of this autoimmunity syndrome is the large scale agglutination of spermatozoa due to the presence of high concentrations of anti-sperm $\mathrm{IgG}$ in seminal plasma. In such circumstances there can be no doubt that these antibodies are the causative factors underlying the infertility syndrome since their presence effectively reduces the number of free motile spermatozoa in the ejaculate. The problem for the clinician has been in determining whether (1) low concentrations of anti-sperm antibodies in seminal plasma, which do not induce large-scale autoagglutination, impair the fertilizing capacity of spermatozoa and (2) isoantibodies in the female partner play any role in the aetiology of infertility; existing information is contradictory in both these areas (Rumke, 1974; Shulman, 1974; Alexander, 1977). These problems have arisen partly because the groups of patients examined by certain authors have been inadequately controlled and/or categorized and partly because of defects in the tests used to detect the presence of antibody (Shulman, 1974). Several antibody detection systems have been employed in such studies, most based upon the ability of antisera to agglutinate or immobilize spermatozoa. There would, of course, be no disadvantage in such a variety of techniques if they all gave comparable results, but this is not the case. In Table 4, the antibody titres are given for 2 antisera, one heterologous and one homologous, assayed by 5 separate methods. The titres obtained vary from 1:80 to 1:10240 for the heterologous antiserum and from undetectable levels to $1: 1024$ for the homologous antiserum according to the assay method used. In order to unravel the possible role that immunological factors might play in the induction of infertility, it will first be necessary to determine the most appropriate test for measuring anti-sperm antibody titres, i.e. to ascertain which of the techniques described in Table 4 yields the most accurate information on the relative ability of these antisera to interfere with the fertilizing capacity of spermatozoa. An experiment was therefore designed in which homologous and heterologous antisera were examined for anti-sperm antibodies

Table 4. Examples of the variation in antibody titres obtained with different monitoring techniques

\begin{tabular}{lcc}
\hline & \multicolumn{2}{c}{ Antiserum } \\
\cline { 2 - 3 } \multicolumn{1}{c}{ Technique } & Heterologous* & Homologous (WHO 118) $\dagger$ \\
\hline Tube-slide agglutination test & $1: 80$ & 0 \\
Gelatin agglutination test & $1: 10240$ & $1: 1024$ \\
Tray agglutination test & $1: 256$ & $1: 256$ \\
Immobilization test & $1: 5120$ & 0 \\
Indirect immunofluorescence & $1: 80$ & - \\
\hline
\end{tabular}

* Raised in a rabbit by 2 intravenous injections 3 weeks apart, of $400 \times 10^{6}$ and $150 \times 10^{6}$ human spermatozoa washed 3 times in Dulbecco's phosphatebuffered saline $+1 \%$ PVP.

† Obtained from the World Health Organization's Reference Bank for Reproductive Immunology, Aarhus, Denmark. 
using a variety of methods and subsequently compared for their ability to inhibit the fertilizing capacity of human spermatozoa in vitro (J. Dor, E. A. Rudak \& R. J. Aitken, unpublished observations).

The measurement of fertilizing capacity was the zona-free hamster egg penetration test first described by Yanagimachi, Yanagimachi \& Rogers (1976). In this procedure, freshly ovulated hamster eggs are stripped of their zonae by treatment with $0.1 \%$ trypsin and then exposed to suspensions of capacitated spermatozoa. Naked hamster oocytes prepared in this way can be penetrated by spermatozoa from a variety of species, including the rat, mouse (Hanada \& Chang, 1972, 1976), guinea-pig (Yanagimachi, 1972), boar (Imai, Niwa \& Iritani, 1977), rabbit, deer mouse (Hanada \& Chang, 1978) and man (Yanagimachi et al., 1976). The criterion for penetration is conventionally the percentage of eggs possessing swollen sperm heads after a 3-h incubation period and 25-50 ova are normally used to assess each sperm sample. Using this test system we have demonstrated that spermatozoa from fertile and infertile men exhibit widely different capacities to penetrate zona-free hamster eggs and that there is no overlap in the range of results obtained for these respective groups (Table 5) (R. J. Aitken, E. A. Rudak, F. Newman, O. Djahabakhch, D. W. Richardson \& A. A. Templeton, unpublished observations). These data strongly suggest that the results obtained with the test do reflect the fertilizing capacity of the specimens examined. Although this test does not directly assess the ability of spermatozoa to traverse the zona pellucida, it is probably significant that, as with the zona pellucida, the penetration of zona-free hamster eggs can only be achieved by spermatozoa of good motility which have undergone the acrosome reaction (Yanagimachi, 1977).

Table 5. Zona free-hamster egg penetration rates observed with spermatozoa from men of differing fertility status

\begin{tabular}{lccc}
\hline \multirow{2}{*}{ Category } & & \multicolumn{2}{c}{ Penetration rate (\%) } \\
\cline { 3 - 4 } & $\mathrm{N}$ & Mean & Range \\
\hline Proven fertility & 24 & $55 \cdot 5$ & $11 \cdot 7-100$ \\
Presumed fertility & 16 & $52 \cdot 0$ & $11 \cdot 6-98$ \\
Infertile & 12 & $1 \cdot 2$ & $0-5 \cdot 2$ \\
\hline
\end{tabular}

A comparison of the antibody titres obtained for 6 anti-sperm antisera (5 homologous, 1 heterologous) and their relative antifertility activity in the zona-free hamster egg penetration test is given in Table 6 . It is clear from these results that only the Franklin-Dukes tube-slide test gives results which bear any resemblance to the relative ability of the respective antisera to inhibit the fertilizing capacity of human spermatozoa. A second finding to come out of this study was the amplifying effect of complement. For example, the ability of a heterologous rabbit anti-sperm antibody to inhibit the fertilizing capacity of human spermatozoa significantly was increased from a titre of $1: 160$ to $1: 320$ by the addition of complement. Similarly, the antifertility activity of an homologous antiserum (WHO 106) was increased from 1:40 to 1:60 when complement was present in the incubation medium. Since complement is present in the secretions of the female reproductive tract, these findings emphasize the importance of including this factor in any in-vitro assessment of the activity of anti-sperm antibodies. The correlation observed between the results obtained with the tube-slide test and the serum dilution at which the fertilizing capacity of human spermatozoa was inhibited may be related to the fact that this test is particularly sensitive for antibodies directed against the sperm head (Boettcher, Hjort, Rumke, Shulman \& Vyazov, 1977). In the presence of complement such antisera would be expected to damage the plasma membranes overlying the sperm head, thereby interfering 
with the acrosome reaction and destroying the integrity of the binding sites for the zona pellucida and/or the oolemma. Similar conclusions have been reached as a result of experiments employing univalent sperm antibodies to block fertilization in vitro (Tzartos, 1979).

Table 6. Agglutination, immobilization and infertility titres* obtained for heterologous and homologous antisperm antisera

Techniques of titre assessment

\begin{tabular}{lccccc}
\hline & \multicolumn{5}{c}{ Techniques of titre assessment } \\
\cline { 2 - 6 } \multicolumn{1}{c}{ Antiserum } & $\begin{array}{c}\text { Tube-slide } \\
\text { agglutination } \\
\text { test }\end{array}$ & $\begin{array}{c}\text { Tray } \\
\text { agglutination } \\
\text { test }\end{array}$ & $\begin{array}{c}\text { Gelatin } \\
\text { agglutination } \\
\text { test }\end{array}$ & $\begin{array}{c}\text { Immobilization } \\
\text { test }\end{array}$ & $\begin{array}{c}\text { Anti } \\
\text { fertility } \\
\text { activity }\end{array}$ \\
\hline Heterologous & $1: 80$ & $1: 10240$ & $1: 256$ & $1: 5120$ & $1: 160$ \\
Homologous (WHO 106) $\dagger$ & $1: 40$ & $1: 256$ & $1: 64$ & $1: 512$ & $1: 40$ \\
Homologous (WHO 38) & $1: 20$ & $1: 64$ & $1: 4$ & 0 & $1: 40$ \\
Homologous (WHO 55) & 0 & $1: 32$ & $1: 32$ & $1: 4$ & 0 \\
Homologous (WHO 95) & 0 & $1: 256$ & $1: 256$ & $1: 32$ & 0 \\
Homologous (WHO 118) & 0 & $1: 1024$ & $1: 256$ & 0 & 0
\end{tabular}

* Dilution of antiserum at which the \% of zona free hamster eggs penetrated by treated spermatozoa was significantly $(P<0.05)$ inhibited with respect to control incubations.

$\uparrow$ Antisera obtained from the World Health Organization's Reference Bank for Reproductive Immunology, Aarhus, Denmark.

In clinical terms, these results suggest that the most appropriate test for assessing the concentration of anti-sperm antibodies in seminal plasma or female blood serum would be the tube-slide test, possibly in conjunction with a technique such as indirect immunofluorescence or the mixed antiglobin reaction to confirm that the observed agglutination has an immunological cause. In cervical mucus, where anti-sperm antibodies may act by interfering with the transport rather than the fertilizing capacity of spermatozoa the more sensitive gelatin or tray agglutination test might be suitable.

\section{References}

Aitken, R.J. \& Richardson, D.W. (1981) Immunization against zona pellucida antigens. In Advances in Immunological Aspects of Reproduction. Ed. J. Hearn. MTP Press, Lancaster (in press).

Alexander, N.J. (1977) Sperm antibodies and infertility. In Male Infertility, Work Up, Treatment and Research, pp. 123-144 Eds A. T. K. Cockett \& R. L. Urry. Academic Press, London.

Boettcher, B., Hjort, T., Rumke, Ph., Shulman, S. \& Vyazov, O.E. (1977) Auto- and iso-antibodies to antigens of the human reproductive system. Acta Path. Microbiol. Scand. Sect. C. Suppl. 258, 1-69.

Dunbar, B.S. \& Raynor, B.D. (1980) Characterization of porcine zona pellucida antigens. Biol. Reprod. 22, 941-954.

Glass, L.E. \& Hanson, J.E. (1974) Immunological approach to contraception: localization of antiembryo and anti-zona pellucida serum during mouse preimplantation. Fert. Steril. 25, 484-493.

Gwatkin, R.B.L. (1977) Fertilization Mechanisms in Man and Mammals. Plenum Press, New York.

Gwatkin, R.B.L. \& Williams, D.T. (1977) Receptor activity of hamster and mouse solubilized zona pellucida before and after the zona reaction. $J$. Reprod. Fert. 49, 55-59.
Gwatkin, R.B.L., Williams, D.T. \& Carlo, D.J. (1977) Immunization of mice with heat solubilized hamster zonae; production of anti-zona antibody and inhibition of fertility. Fert. Steril. 28, 871-877.

Hanada, A. \& Chang, M.C. (1972) Penetration of zonafree eggs by spermatozoa of different species. Biol. Reprod. 6, 300-309.

Hanada, A. \& Chang, M.C. (1976) Penetration of hamster and rabbit zona-free eggs by rat and mouse spermatozoa with special reference to sperm capacitation. J. Reprod. Fert. 46, 239-241.

Hanada, A. \& Chang, M.C. (1978) Penetration of the zona-free or intact eggs by foreign spermatozoa and the fertilization of deer mouse eggs in vitro. J. exp. Zool. 203, 277-286.

Imai, H., Niwa, K. \& Iritani, A. (1977) Penetration in vitro of zona-free hamster eggs by ejaculated boar spermatozoa. J. Reprod. Fert. 51, 495-497.

Jilek, F. \& Pavlok, A. (1975) Antibodies against mouse ovaries and their effect on fertilization in vitro and in vivo in the mouse. J. Reprod. Fert. 42, 377-380.

Mori, T., Nishimoto, T., Kohda, H., Takai, I., Nishimura, T. \& Oikawa, T. (1979) A method for specific detection of auto antibodies to the zona pellucida in infertile women. Fert. Steril. 32, 67-72. 
Nicolson, G.L., Yanagimachi, R. \& Yanagimachi, H. (1975) Ultrastructural localization of lectin-binding sites on the zonae pellucidae and plasma membranes of mammalian eggs. J. Cell Biol. 66, 263-274.

Oikawa, T. \& Yanagimachi, R. (1975) Block of hamster fertilization by anti-ovary antibody. J. Reprod. Fert. 45, 487-494.

Porter, C., Highfill, D. \& Winovich, R. (1970) Guinea pig ovary and testis: demonstration of common gonad specific antigens in the ovary and testis. Int. $J$. Fertil. 15, 171-176.

Rumke, P. (1954) The presence of sperm antibodies in the serum of two patients with oligozoospermia. Vox Sang. 4, 135-137.

Rumke, P. (1974) Autoantibodies against spermatozoa in infertile men: some unsolved problems. In Immunology in Obstetrics and Gynaecology, pp. 26-35. Eds A. Centaro \& N. Carretti. Excerpta Medica, Amsterdam.

Sacco, A.G. (1977) Antigenic cross-reactivity between human and pig zona pellucida. Biol. Reprod. 16, 164-173.

Sacco, A.G. (1979) Inhibition of fertility in mice by passive immunization with antibodies to isolated zonae pellucidae. J. Reprod. Fert. 56, 533-537.

Sacco, A.G. \& Shivers, C.A. (1973) Localization of tissue-specific antigens in the rabbit ovary, oviduct and uterus by the fluorescent antibody technique. J. Reprod. Fert. 32, 415-420.

Shivers, C.A. (1974) Immunological interference with fertilization. Acta endocr., Copenh., Suppl. 194, 223-244.

Shivers, C.A., Dudkiewicz, A.B., Franklin, L.E. \& Fussell, E.N. (1972) Inhibition of sperm-egg interaction by specific antibody. Science, N.Y. 178, 1211-1213.

Shulman, S. (1974) Sperm antibodies in the serum and cervical mucus of women. In Immunology in Obstetrics and Gynaecology, pp. 87-93. Eds A. Centaro \& N. Carretti. Excerpta Medica, Amsterdam.
Tsunoda, Y. (1977) Inhibitory effect of anti-mouse egg serum on fertilization in vitro and in vivo in the mouse. J. Reprod. Fert. 50, 353-355.

Tsunoda, Y. \& Chang, M.C. (1976a) Effect of anti-rat ovary antiserum on the fertilization of rat, mouse and hamster eggs in vivo and in vitro. Biol. Reprod. 14, 354-361.

Tsunoda, Y. \& Chang, M.C. (1976b) In vivo and in vitro fertilization of hamster, rat and mouse eggs after treatment with anti hamster ovary antiserum. J. exp. Zool. 195, 409-416.

Tsunoda, Y. \& Chang, M.C. (1977) Further studies on antisera on the fertilization of mouse, rat and hamster eggs in vivo and in vitro. Int. J. Fert. 22 , 129-133.

Tsunoda, Y. \& Chang, M.C. (1978) Effect of antisera against eggs and zonae pellucidae on fertilization and development of mouse eggs in vivo and in culture. J. Reprod. Fert. 54, 233-237.

Tsunoda, Y. \& Sugie, T. (1977) Effect of isoimmunization with cumulus-free eggs on reproduction in mice. Jap. J. Zootech. Sci. 49, 319-322.

Tzartos, S.J. (1979) Inhibition of in-vitro fertilization of intact and denuded hamster eggs by univalent antisperm antibodies. J. Reprod. Fert. 55, 447-455.

Wilson, L. (1954) Sperm agglutinins in human semen and blood. Proc. Soc. exp. Biol. Med. 85, 652-660.

Yanagimachi, R. (1972) Penetration of guinea pig spermatozoa into hamster eggs in vitro. J. Reprod. Fert. 28, 477-480.

Yanagimachi, R. (1977) Specificity of sperm-egg interaction. In Immunobiology of Gametes, pp. 255-295. Eds M. Edidin \& M. H. Johnson. Cambridge University Press.

Yanagimachi, R., Yanagimachi, H. \& Rogers, B.J. (1976) The use of zona-free animal ova as a test system for the assessment of the fertilizing capacity of human spermatozoa. Biol. Reprod. 15, 471-476. 